\title{
O PAPEL DOS AUTORES NOS REPOSITÓRIOS INSTITUCIONAIS
}

\author{
Bruno Pinheiro Neves \\ Universidade de Coimbra (Portugal) \\ Maria Manuel Borges \\ Universidade de Coimbra (Portugal)
}

\section{Introduçáo}

A publicação da BOAI (Budapest Open Access Iniative), em 2002, delineou um modelo estratégico para o acesso a livre à informação científica, reforçando o objectivo do movimento Open Access, através de duas vias complementares: a via dourada, com a publicação em revistas de livre acesso, e a via verde, através do auto-arquivo em repositórios.

A via verde tem como principal propósito assegurar que o trabalho produzido pelos autores, na sua versão preprint e/ou postprint, seja amplamente difundido, e, consequentemente, citado. Neste processo, os autores, ao aderirem a um sistema que lhes garante uma maior visibilidade, devido ao facto dos seus trabalhos poderem ser lidos pela comunidade científica e público em geral, potenciam o impacto de citação.

\section{Objectivos e Metodologia}

Pretende-se evidenciar comportamentos e reacçóes dos autores, em relação às questôes do acesso livre à informação científica e à sua difusão, bem como demonstrar o grau de abertura dos autores para o auto-arquivo da sua produção científica no repositório institucional da Universidade de Coimbra, o 'Estudo Geral'. Os resultados obtidos foram sustentados no inquérito aos investigadores das Unidades de Investigaçáo da Universidade de Coimbra (Borges, 2006). De forma a avaliar as experiências de repositórios com políticas de auto-arquivo distintas e desenhar a metodologia conducente a um aumento da participação dos investigadores, foram analisados três repositórios de universidades americanas (Massachusetts Institute of Technology, Cornell University e Columbia University).

\section{Resultados e Discussão}

Quando questionados sobre a submissão de trabalhos em repositórios institucionais ou temáticos, como forma de ampliar a difusão da informação científica, a maioria dos autores respondeu de um modo positivo. Segundo os dados do Ministério da Ciência, Tecnologia e Ensino Superior, durante o quinquénio de 2004-2008, foram publicados 
31138 artigos, nas principais revistas internacionais. Contudo apenas 15\% (4705) dos artigos foram depositados nos repositórios nacionais, durante o mesmo período. Das teses de doutoramento realizadas nas universidades portuguesas entre 2004 e 2008, apenas 13\% (728) se encontram nos repositórios das instituiçóes.

A maioria dos autores (78\%), aceitaria sem problemas um mandato obrigatório da Universidade de Coimbra, o que confirma os dados obtidos em outros estudos (mais de 80\% segundo o estudo de Swan e Brown, 2005). Pela análise efectuada aos repositórios de universidades americanas podemos observar que o crescimento do número de depósitos onde o auto-arquivo é obrigatório (MIT, 32380), é bastante superior em relação a outros repositórios onde não é aplicado (Columbia, $11700 \mathrm{e}$ Cornell, 11790). Mesmo com políticas de depósito voluntário (Cornell), sensibilizando autores e comunidades para a importância do auto-arquivo, o aumento de número de documentos depositados não é significativo. Estas políticas de incentivo ao autoarquivo nem sempre são eficientes, conferindo uma percentagem de êxito no valor de $20 \%$ (Sale, 2006). Ainda que o número de mandatos ao auto-arquivo tenha proliferado nos últimos anos, 129 até ao momento, apenas em 15\% dos repositórios, dos mais de 1400 repositórios existentes, é obrigatório o depósito da produção científica dos investigadores de cada instituição.

Em Portugal, somente a Universidade do Minho, uma das pioneiras a nível mundial, implementou o auto-arquivo mediante mandato. Os resultados obtidos, tal como em outros repositórios que adoptam a mesma política de auto-arquivo, reflectem-se na visibilidade e impacto da instituição a nível mundial. Na edição de Julho de 2009, no Ranking Web of World Repositories, o RepositóriUM ocupou a 16 a posição e o MIT na $5^{\text {a }}$ posição, no universo dos repositórios institucionais.

Em relação à disponibilizaçáo dos trabalhos dos autores na Web, a maioria tem receio do plágio ou com a quebra de eventuais compromissos com os editores. Além destes receios, segundo o estudo de Swan e Brown (2005), existem ainda outros factores de resistência por parte dos autores, dentro dos quais: o tempo despendido e as eventuais dificuldades técnicas, durante o processo de submissão de trabalhos. De forma a minimizar as dificuldades que possam surgir e reduzir a morosidade no processo de submissão de materiais, os responsáveis pelo repositório deveráo implementar serviços de apoio mediados pelo bibliotecário, guias e sistemas de ajuda. Além disso, é imprescindível esclarecer os autores das políticas de depósito adoptadas, salvaguardando os direitos essenciais à propriedade intelectual, e informando-os para as restriçôes impostas pelas editoras. Os investigadores, ao depositarem os seus trabalhos no repositório da sua instituiçáo, possibilitam que os seus trabalhos tenham uma maior acessibilidade e disseminação. A interoperabilidade entre os repositórios é facultada pelo Open Archives Initiative Protocol for Metadata Harvesting. Este protocolo possibilita a agregação em repositórios temáticos, nacionais (RCAAP, Recolecta, NARCIS, PUMA), redes europeias (DRIVER), mundiais (OAIster), e passíveis de serem recuperados pelo Google Scholar, CiteSeer etc. Assim sendo, é necessário que todas as partes intervenientes no processo colaborem no mesmo sentido: implementando políticas e medidas que levem ao auto-arquivo, beneficiando os autores com um maior acesso à informação cientifica e aumento das probabilidades de citação, e consequentemente as instituiçóes e agências de financiamento, com maior prestígio e visibilidade perante a comunidade científica mundial. 


\section{Referências bibliográficas}

BORGES, Maria Manuel (2006) - A Esfera: Comunicação Académica e Novos Media. Coimbra: Universidade. Faculdade de Letras. Tese de doutoramento

PORTUGAL. Ministério da Ciência, Tecnologia e Ensino Superior. GPEARI (2009) - Produção Cientifica Portuguesa, 1981-2008: Indicadores Bibliométricos. Lisboa: GPEARI. ISBN 978972-8844-41-7. [Acedido em 2009-08-29]. Disponível na WWW: http://www.gpeari.mctes. pt/archive/doc/Indicadoresbibliometricos_1981_2008__2.pdf

SALE, A. (2006) - A researcher's viewpoint In: Open Access: Key Strategic, Technical and Economic Aspects. Oxford: Chandos Publishing Limited. ISBN 1843342030. P. 87-100. [Acedido em 2009-02-15]. Disponível na WWW: http://eprints.utas.edu.au/257/1/Chapter.pdf

SWAN, A.; BROWN, S. N. (2005) - Open access self-archiving: An author study . JISC, 2005 [Acedido em 2009-02-10]. Disponível na WWW: http://cogprints.org/4385/.

Registry of Open Access Repositories (ROAR). [Acedido em 2009-08-29]. Disponível na WWW: http://roar.eprints.org/index.php 